\title{
Influence of salinity $(\mathrm{NaCl})$ on the photosynthetic pigments content of some sweet sorghum varieties
}

\author{
Gulnaz Baiseitova ${ }^{1, *}$, Batyrbek Sarsenbayev ${ }^{2}$, Erlan Kirshibayev $^{2}$, and Madiar Kamunur ${ }^{1}$ \\ ${ }^{1}$ Kazakh National Agrarian University, Almaty, 050010, Republic of Kazakhstan \\ ${ }^{2} \mathrm{RSE}$ «Institute of Plant Biology and Biotechnology», Almaty, 050040, Republic of Kazakhstan
}

\begin{abstract}
Identification and introduction of crops into the production that are sufficiently adapted to drought and salinization of soils capable of providing high productivity with limited water consumption is becoming increasingly important currently, and in particular in prospect under the circumstances of aggravating of climate aridization and desertification processes in the Central Asian region. These requirements are met by sorghum, the main economic features of which are universality of use, exceptional heat,-- drought,- and salt tolerance, as well as high productivity. The article presents the results of studying the effect of a saline nutrient medium on the content of photosynthetic pigments in some varieties of sweet sorghum to identify the most resistant varieties to chloride salinity. It was shown that the concentration of $\mathrm{a}$ and $\mathrm{b}$ chlorophylls, as well as carotinoids in leaves decreases with increasing $\mathrm{NaCl}$ concentration. The content of photosynthetic pigments under conditions of salinity was higher in resistant varieties than in unstable varieties. The quantitative content of photosynthetic pigments affects the intensity and productivity of photosynthesis which determines the yield of agricultural crops.
\end{abstract}

\section{Introduction}

Saline soils occupy $20 \%$ of the world's developed lands, and half of all irrigated lands are highly salinized. The tendency of soil salinity growth persists. For example, 900 million hectares in the world are valued as salinized land which accounts for approximately $6 \%$ of all world soils or about $20 \%$ of the world's developed territories [1,2].

The irrational use of natural resources leads to environmental disruption. The total area of Kazakhstan is 272 million hectares, and of these 180 million hectares is currently threatened with degradation which is $60 \%$ of the total territory of the country. Degradation is accompanied by intensive salinization of the soil which leads to an increase in the territory of saline desert areas in the internal drainage basins and salinization of irrigated lands [3]. The number of cultivated plants that can grow on saline soils is insignificant. One such plant is sorghum.

\footnotetext{
Corresponding author: b.g.naz@mail.ru
} 
Sorghum is a unique cereal plant, both for its biological characteristics and for its economically valuable characteristics. Its main advantages are exceptional drought tolerance, salt tolerance, high productivity, stable yields by year, good fodder dignity and universality of use $[4,5,6,7]$.

Sorghum tolerates soil salinity better than other crops [8,9]. This culture is able to grow normally and develop at a salt concentration in the soil two times higher than that required by corn. This culture, perhaps, can be cultivated on almost all soils except wet and cold soils with a close standing of groundwater [10].

Sorghum is a good meliorating crop when sown on alkali soils and a reliable remedy for combating secondary salinization. Thus, variety crops not only provide high yields of grain and green mass, but also take out salts from the soil from 31 to 75 tons per hectare, including harmful ones, such as chlorides and sulfates. Sorghum forms a large biomass of plant residues which ultimately enriches the soil with organic substance and serves as a phytomeliorant [11].

The cultivation of sweet sorghum in the Republic of Kazakhstan, to a considerable extent, may save irrigation water (resource-saving), restore soil fertility (desalinization, improve water-physical properties), improve ecology (regulation of atmospheric humidity and temperature, $\mathrm{O} 2 / \mathrm{CO} 2$ balance), provide the population with liquid sugar, livestock farms with forages, solve the problems of energy in the region (biofuel).

In connection with the abovementioned, we conducted a comparative assessment of sugar sorghum varieties for salt tolerance in order to identify and select the most promising varieties for cultivation on saline soils in southeast Kazakhstan. The quantitative content of photosynthetic pigments was used as criteria for salt tolerance.

\section{Materials and Methods}

Domestic and foreign varieties (15 varieties) of sweet sorghum (Sorghum saccharatum Pers.) were taken as the object of research. The plants were grown 10 days in solutions containing various salt concentrations: control, $0.3 \%, 0.6 \%, 0.9 \% \mathrm{NaCl}$. Determination of photosynthetic pigments was carried out using the Shlyk method [13]. Extraction of chlorophylls «a» and «b», as well as carotinoids from leaves was carried out by the alcohol extraction method, and their concentration was found by spectrophotometric method (SFGenesys $10 \mathrm{uv}$ ) at 649 (644) and 665 (662) nm, carotinoids at 440,5 nm. The pigment content was calculated by the formulas (Werner formulas):

$$
\begin{aligned}
& C A(m g / l)=11,63 \times D 665-2,39 \times D 649 \\
& C B(m g / l)=20,11 \times D 649-5,18 \times D 665
\end{aligned}
$$

The content of carotinoids was determined by the Wettstein's formula:

$$
\operatorname{Ccar}(m g / l)=4,695 \times D 440,5-0,268 \times(C A+B m g / l)
$$

Conversion of the pigment content to $\mathrm{mg} / \mathrm{g}$ was carried out according to the formula:

$$
A=C x V / P x 1000
$$

where $\mathrm{A}$ is the pigment content, $\mathrm{mg} / \mathrm{g} ; \mathrm{C}$ is the concentration of chlorophyll, $\mathrm{mg} / \mathrm{l} ; \mathrm{V}$ is the volume of drawing, $\mathrm{ml} ; \mathrm{P}$ is the weight, $\mathrm{g}$.

All research results were subjected to statistical processing by Udolskaya [14] and computer programs Excel 97, ANOVASYSTAT 2007. 


\section{Results and discussion}

A study of the content of photosynthetic pigments in sweet sorghum varieties showed that a weak concentration of $\mathrm{NaCl}(0.3 \%)$ stimulated the formation of chlorophyll a in the leaves of varieties Kazakhstanskoye-16, Sever, Stavropol-36, Larets, Borotala and Sazhen. High salt concentrations (0.6-0.9\%) suppressed the formation of chlorophyll a more in varieties Rostovskyi, Oranzhevoye-160, Sakharnoye-32 (Figure 1).

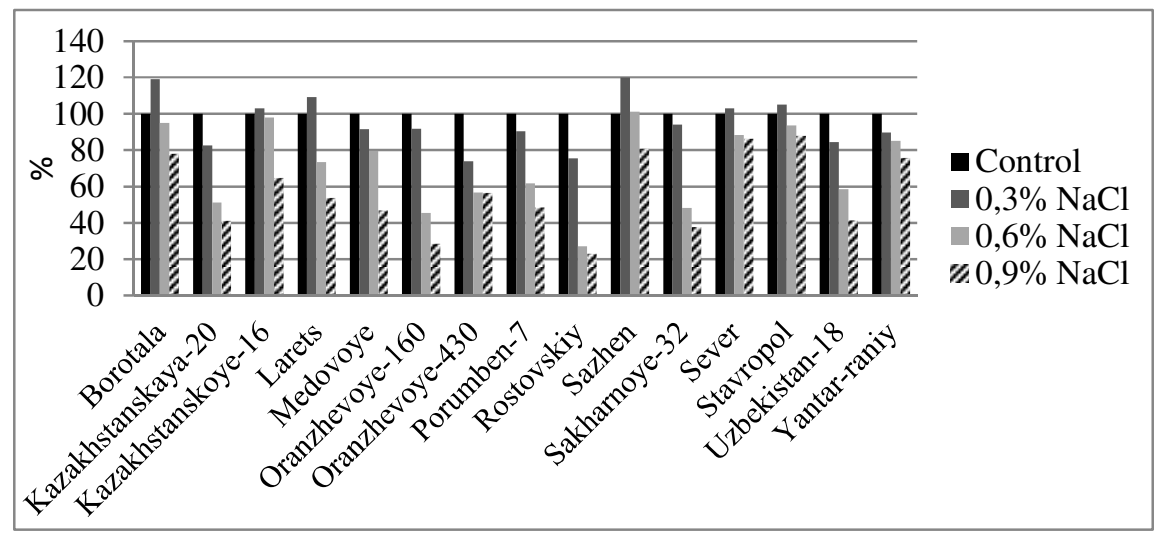

Fig. 1. Influence of salinity on the content of chlorophyll a in leaves of sweet sorghum varieties.

Similar results were obtained when analyzing the content of chlorophyll $b$ in leaves of sweet sorghum varieties. Weak salinity caused an increase in the content of chlorophyll $b$ in varieties Sazhen, Stavropol-36, Uzbekiston-18 and Borotala. A sharp decrease in the pigment content under the influence of salt was found in the Rostovskyi variety. The content of this pigment was less affected by salinity in the varieties Sever, Stavropol-36 and Uzbekistan-18 (Fig. 2).

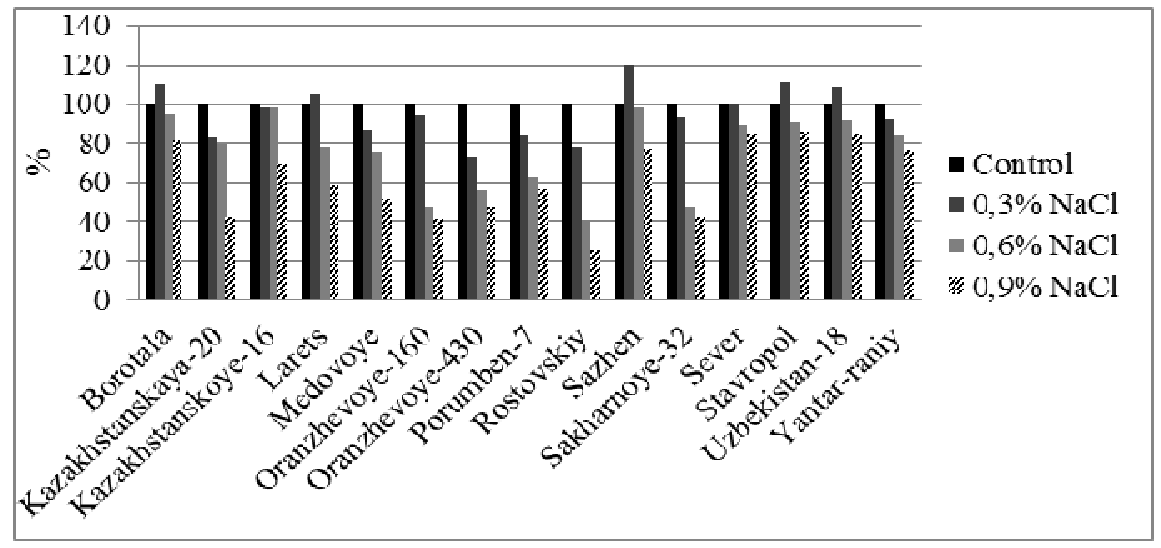

Fig. 2. Influence of salinity on the content of chlorophyll $b$ in leaves of sweet sorghum varieties.

Carotinoids are involved in various defense mechanisms: due to the presence of conjugated double bonds. They are able to bind singlet oxygen and inhibit the formation of free radicals preventing their negative effect on the organism. They can also act as antioxidants protecting sensitive tissues and labile compounds from oxidation. It can be assumed that adverse environmental factors can induce the synthesis of carotinoids, especially in stress-resistant samples. 
Indeed, a weak concentration of chloride salinity increased the content of carotinoids to $17-18 \%$ in varieties (Figure 3).

Sazhen and Stavropol-36 differ in relative resistance to salinity. The content of this pigment increased to $5-6 \%$ in varieties Larets and Sever which also were resistant to salinity.

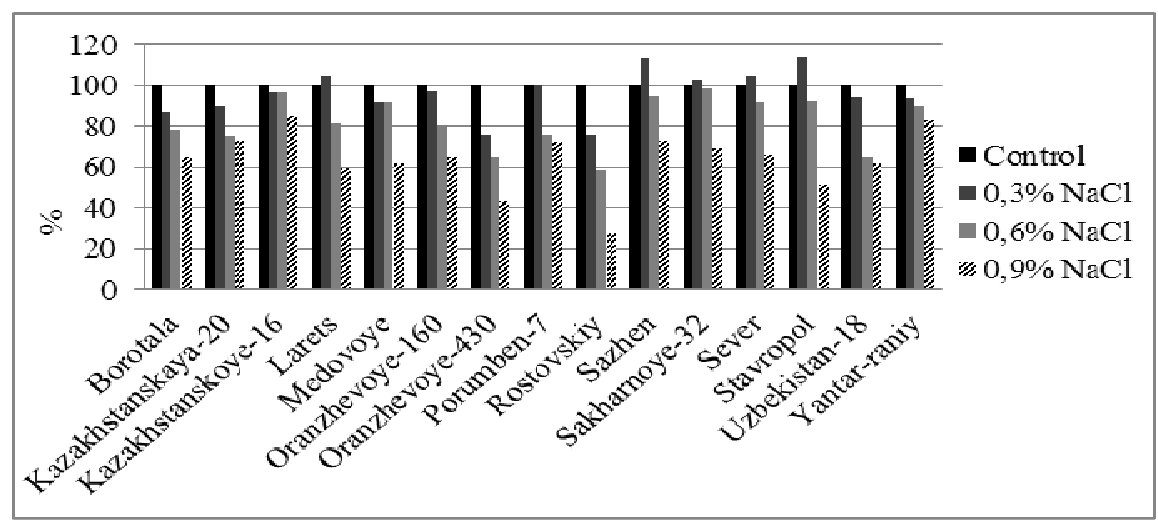

Fig. 3. Influence of salinity on the content of carotinoids in leaves of sweet sorghum varieties.

Thus, this characteristic, the quantitative content of carotinoids can be used as a marker of resistance of varieties to salinity.

As a result of studies of 15 different varieties of sweet sorghum we detected relatively salt-resistant forms for the content of photosynthetic pigments that can be grown in slightly saline soils, and can also be used as a starting material for obtaining more stable forms of sweet sorghum.

\section{References}

1. T. Flowers, Journal of Experimental Botany 55, 307-319 (2004)

2. R. Munns, M. Tester, Ann. Rev. Plant Biol. 59, 651-681 (2008)

3. M.A. Orlova, A.S. Saparov, Global self-regulating circulation of salts in nature. (Almaty, 2009)

4. N.I. Nesmeyanova, Features of the soil cover and the fertility condition of arable soils in the Samara Region (Kinel, 2002)

5. A.V. Alabushev. Adaptive technology of grain sorghum cultivation to the arid zone of the Northern Caucasus (Zernograd, 2000)

6. A.P. Tsarev E.V. Morozov, Agrobiological bases of cultivation and use of sorghum crops in the Volga region (Sarayov, 2011)

7. O.A. Pergayev, Corn and sorghum 1, 29-32 (2013)

8. Y.I. Isakov, Agriculture of Russia 4, 14-22 (1977)

9. B.N. Malinovskyi, Steppe areas 9, 24-28 (1981)

10. L.P. Beltyukov, A.A. Gritsenko. Application of fertilizers for grain crops in the Don (Collection of scientific work. Institute of sorghum,Zernograd, 1993)

11. G. Levakhin, Y. Sidorov, N. Dokina, Milk and meat cattle breeding 8, 20-23 (2010)

12. A.A. Shlyk, Biochemical methods in plant physiology (Nauka, Moscow, 1971)

13. N.L. Udolskaya. Introduction to Biometrics. (Nauka, Alma-Ata, 1976) 